\title{
Effect of implementation of Integrated Management of Neonatal and Childhood IIIness programme on treatment seeking practices for morbidities in infants: cluster randomised trial
}

\author{
(c) $\underset{1}{(1)(8)}$ OPEN ACCESS
}

Sarmila Mazumder deputy director ${ }^{1}$, Sunita Taneja deputy director ${ }^{1}$, Rajiv Bahl medical officer ${ }^{2}$, Pavitra Mohan health specialist ${ }^{3}$, Tor A Strand professor ${ }^{4}$, Halvor Sommerfelt director ${ }^{5}$, Betty $\mathrm{R}$ Kirkwood professor, epidemiology and international health ${ }^{6}$, Nidhi Goyal scientist ${ }^{1}$, Henri Van Den Hombergh chief (health section) ${ }^{3}$, Jose Martines scientific coordinator ${ }^{5}$, Nita Bhandari director ${ }^{1}$, on behalf of the Integrated Management of Neonatal and Childhood Illness Evaluation Study Group

${ }^{1}$ Centre for Health Research and Development, Society for Applied Studies, New Delhi 110016, India; ${ }^{2}$ Department of Maternal, Newborn, Child and Adolescent Health, World Health Organization, Geneva, Switzerland; ${ }^{3}$ UNICEF India Country Office, New Delhi, India; ${ }^{4}$ Centre for International Health, University of Bergen, Norway; ${ }^{5}$ Centre for Intervention Science in Maternal and Child Health, Centre for International Health, University of Bergen, Norway; ${ }^{6}$ London School of Hygiene and Tropical Medicine, London, UK

\author{
Abstract \\ Objective To determine the effect of implementation of the Integrated \\ Management of Neonatal and Childhood Illness strategy on treatment \\ seeking practices and on neonatal and infant morbidity. \\ Design Cluster randomised trial. \\ Setting Haryana, India \\ Participants 29667 births in nine intervention clusters and 30813 births \\ in nine control clusters.
}

Main outcome measures The pre-specified outcome was the effect on treatment seeking practices. Post hoc exploratory analyses assessed morbidity, hospital admission, post-neonatal infant care, and nutritional status outcomes.

Interventions The Integrated Management of Neonatal and Childhood Illness intervention included home visits by community health workers, improved case management of sick children, and strengthening of health systems. Outcomes were ascertained through interviews with randomly selected caregivers: 6204, 3073, and 2045 in intervention clusters and 6163, 3048, and 2017 in control clusters at ages 29 days, 6 months, and 12 months, respectively.

Results In the intervention cluster, treatment was sought more often from an appropriate provider for severe neonatal illness (risk ratio 1.76, $95 \%$ confidence interval 1.38 to 2.24 ), for local neonatal infection (4.86, 3.80 to 6.21$)$, and for diarrhoea at 6 months $(1.96,1.38$ to 2.79$)$ and 12 months $(1.22,1.06$ to 1.42$)$ and pneumonia at 6 months $(2.09,1.31$ to
3.33) and 12 months (1.44, 1.00 to 2.08). Intervention mothers reported fewer episodes of severe neonatal illness (risk ratio $0.82,0.67$ to 0.99 ) and lower prevalence of diarrhoea $(0.71,0.60$ to 0.83$)$ and pneumonia $(0.73,0.52$ to 1.04$)$ in the two weeks preceding the 6 month interview and of diarrhoea $(0.63,0.49$ to 0.80$)$ and pneumonia $(0.60,0.46$ to 0.78$)$ in the two weeks preceding the 12 month interview. Infants in the intervention clusters were more likely to still be exclusively breast fed in the sixth month of life (risk ratio $3.19,2.67$ to 3.81 ).

Conclusion Implementation of the Integrated Management of Neonatal and Childhood IIIness programme was associated with timely treatment seeking from appropriate providers and reduced morbidity, a likely explanation for the reduction in mortality observed following implementation of the programme in this study.

Trial registration Clinical trials NCT00474981; ICMR Clinical Trial Registry CTRI/2009/091/000715.

\section{Introduction}

Neonatal and infant mortality pose a major public health challenge, and progress in reduction over the past years has been slow. In 2011 around 6.9 million children aged under 5 years died globally. ${ }^{1}$ More than $40 \%$ of all deaths in children under 5 occur within the first four weeks of life in the neonatal period. ${ }^{2}$ India contributes approximately $25 \%$ of all neonatal deaths in the world ${ }^{3}$; these account for approximately half of deaths in under 5 year olds in the country. ${ }^{4}$ Although efforts 
targeted to reduce overall mortality in children under 5 have been effective, the proportion of neonatal deaths among the mortality in under 5 years olds has increased. ${ }^{3}$ India adapted the Integrated Management of Childhood Illness Program by adding a neonatal component, renaming it the Integrated Management of Neonatal and Childhood Illness. ${ }^{56}$ The neonatal component additionally focused on promoting essential newborn care through home visits in the first week of life and community mobilisation to reach every newborn. Fifty per cent of training time is dedicated to the young infant. Through this approach, the Integrated Management of Neonatal and Childhood Illness programme aims to improve early recognition and treatment seeking for sick neonates and children. ${ }^{6}$ Implementation of Integrated Management of Neonatal and Childhood Illness started in India in 2003. The programme is now being implemented in 433 of the 640 districts, including in the control clusters (primary health centre catchment areas) in the study. ${ }^{7}$

We evaluated the Integrated Management of Neonatal and Childhood Illness strategy in a cluster randomised trial and found that it resulted in a reduction in infant mortality by $15 \%$ and in neonatal mortality beyond the first 24 hours by $14 \% .^{8}$ Home based newborn care practices such as starting breast feeding within one hour of birth, exclusive breast feeding at 4 weeks, delayed bathing, and appropriate cord care improved substantially in the intervention clusters. ${ }^{8}$ Treatment seeking practices of caregivers in the intervention and control clusters have not previously been reported.

The signs of severe illness in neonates are often subtle and may go undetected by families. Treatment seeking practices in the postnatal period are often suboptimal. ${ }^{9}$ Timely and appropriate treatment seeking has been shown to influence children's survival. ${ }^{10-14}$ Improving the identification of neonatal illnesses and promoting appropriate treatment seeking is likely to have an effect on survival.

Subsequent to reporting the effect of the Integrated Management of Neonatal and Childhood Illness strategy on mortality and newborn caring practices, we now report the effect of its implementation on treatment seeking for neonatal and infant morbidities.

\section{Methods}

\section{Setting}

We conducted the trial in communities with a population of 1.1 million, served by 18 primary health centres in district Faridabad, Haryana, India. ${ }^{8}$ Around half the mothers had never been to school, and two thirds of births occurred at home. Previous studies in the setting showed that $35 \%$ of newborns were born at low birth weight and $60 \%$ of sick children were taken for treatment to private providers who were not medically qualified. ${ }^{15}{ }^{16}$ In the intervention and control primary health centres' catchment areas, the distribution of facilities and healthcare providers was as follows: primary health centre facilities ( 9 intervention/9 control), sub-centres (55/53), medically qualified physicians (38/49), private providers not medically qualified (871/817), auxiliary nurse midwives (63/67), accredited social health activists (289/263), and Anganwadi workers $(481 / 364)$.

\section{Baseline survey and randomisation}

We used the catchment areas of the 18 primary health centres in the district as the unit (clusters) of randomisation for this trial. Information on characteristics required for randomisation was obtained through a door-to-door survey in all the 18 primary health centres (clusters). This included the proportion of home deliveries, proportion of mothers who had never been to school, population, and neonatal and infant mortality. ${ }^{8}$

The 18 clusters, each served by a primary health centre, were divided into three strata containing six clusters each on the basis of the baseline neonatal mortality rates (high, mid, and low). An independent epidemiologist generated 10 stratified randomisation schemes to allocate the clusters to intervention or control groups. We excluded three of these schemes, which had large differences in neonatal mortality rate, proportion of home births, proportion of mothers who had never been to school, and population size. ${ }^{8}$ We selected one of the remaining seven allocation schemes by a computer generated random number.

\section{Intervention}

The intervention and measurement strategy have been described in detail earlier. ${ }^{8}$ The intervention was designed according to the Integrated Management of Neonatal and Childhood Illness guidelines defined by the Government of India. ${ }^{17-20}$ It was implemented from January 2007 to April 2010. The three components of the intervention were as follows.

\section{Home visits during newborn period}

Community health workers in the intervention clusters were trained to conduct home visits and counsel mothers to promote optimal newborn care practices, identify and treat illnesses, and refer sick newborns.

\section{Improving case management skills}

Community health workers and physicians working in the primary health centres in the nine intervention clusters were trained to improve their skills for the case management of sick children aged under 5 by using the Government of India's Integrated Management of Neonatal and Childhood Illness training modules. ${ }^{817-20}$ Private providers in the formal and informal sectors underwent Integrated Management of Neonatal and Childhood Illness orientation sessions. ${ }^{8}$

\section{Strengthening of health system to implement}

The health system was strengthened through improved supervision of community health workers, provision of performance based incentives, and ensuring regular supplies of essential medicines through village level depots. ${ }^{8}$ Women's group meetings were conducted every three months in each village to improve community awareness about the available services. $^{8}$

\section{Outcomes and their ascertainment}

The pre-specified outcome reported here is the effect of the intervention on treatment seeking practices. As a post hoc exploratory analysis, we also report some morbidity, hospital admission, post-neonatal infant care, and nutritional status outcomes (supplementary table A).

The surveillance team visited infants at 1, 3, 6, 9, and 12 months of age for vital status confirmation. We randomly selected subsamples of all infants at enrolment for detailed interviews. One of the main aims of the Integrated Management of Neonatal and Childhood Illness programme is to improve treatment seeking from care providers as a result of improved recognition of illnesses by caregivers. This outcome is critical in promoting neonatal and infant survival and important for assessing the effectiveness of several components of the programme, such as 
home visits and community awareness activities. Caregivers were interviewed by an independent team of research assistants, who were unaware of the intervention status of the communities. The identification numbers of infants selected for interview were communicated to the research assistants a day before the scheduled interview. These interviews lasted between 45 minutes and an hour and were always conducted at the home of the enrolled infant. In most instances the primary caregiver, the mother, was interviewed. Occasionally other family members were present. Interviews were conducted at infant age 29 days (or within the next 14 days) to collect information on treatment seeking practices (the pre-specified outcome), illnesses, and hospital admissions since birth. The 6 month interviews were conducted during the sixth month of life (day 150 to 170) instead of at exactly 6 months of age, because we wanted to ascertain exclusive breast feeding during the recommended period. ${ }^{6}$ During the 6 and 12 month visits, information on treatment seeking for illnesses and presence of pneumonia and diarrhoea in the two week period and hospital admissions in the three months preceding the interview was obtained. The morbidity data were self reported, based on symptoms as perceived by the caregiver. Questions were asked using local terms for diarrhoea and pneumonia. At the 12 month visit, information was also ascertained on complementary feeding practices and immunisation coverage. To assess the nutritional status, weight was measured to the nearest $50 \mathrm{~g}$ by using a Seca hanging scale (Seca, Hamburg, Germany). Length was measured by using locally manufactured infantometers that read to the nearest 0.1 $\mathrm{cm}$. The definitions of pre-specified and post hoc exploratory outcomes are provided in the box.

\section{Study size}

We calculated the sample size for the main trial (66 600 births) for the primary outcomes - that is, infant and neonatal mortality. ${ }^{8}$ Secondary outcomes - that is, home based newborn care practices and treatment seeking for illness-were ascertained through interviews at infant ages 29 days and 6 and 12 months in randomly selected subsamples. We calculated the sample sizes for the secondary outcomes by using the following assumptions. We assumed that, on average, $30 \%$ of newborns who were ill during the neonatal period would be expected to seek care from an appropriate provider, with a coefficient of variation $(\kappa)$ of $\sim 0.1$. We needed 88 sick newborns per cluster (that is, 792 sick newborns per group) to detect a $10 \%$ absolute difference between the intervention and control clusters $(40 \%$ $v 30 \%$; risk ratio 1.33 ) with $90 \%$ power and $95 \%$ confidence. We needed a total of 6600 interviews per group, assuming that about $13 \%$ of the newborns would be sick during the neonatal period and adding $10 \%$ for attrition.

For sample size estimation at 6 and 12 months, we assumed that $15 \%$ of infants at 6 and 12 months would be sick with diarrhoea or pneumonia in the previous two weeks and $50 \%$ of these, with a $\kappa$ of 0.1 , would seek care for illness from an appropriate provider. To detect a $15 \%$ absolute difference between the intervention and control clusters $(65 \% v 50 \%$; risk ratio 1.3$)$ with $90 \%$ power and $95 \%$ confidence, we needed 50 sick children in each cluster at 6 and 12 months (that is, 430 sick children per group). We needed a total of 3300 interviews per group at 6 and 12 months, adding $10 \%$ for attrition, to detect the assumed difference.

During its periodic review, the Data Safety Monitoring Board recommended cessation of enrolment when approximately 60 000 infants had been included in the main trial. ${ }^{8}$ At this point, $12367 / 13200(93.7 \%)$ caregivers had been interviewed at infant age 29 days, $6121 / 6600$ (92.7\%) at 6 months, and 4062/6600
$(61.5 \%)$ at 12 months. As attrition rates were lower than anticipated, the number of interviews that needed to be conducted was lower than estimated. However, the numbers available were sufficient to detect the assumed differences in outcomes between intervention and control groups at approximately $80 \%$ power.

\section{Statistical analysis}

We used Stata software version 10.0 for analysis of data from all available children and caregivers. We used logistic regression to compare morbidity and treatment seeking practices. The resulting coefficients were adjusted for cluster design and two important cluster level differences identified in the baseline survey-namely, the distance between the primary health centre facility and the nearest point on the highway and the proportion of home births in the cluster. ${ }^{8}$ We included the cluster design as a random effect in the model. Other individual level characteristics included as covariates in the model were illiterate mother, toilet within the house, family belonging to schedule caste or tribe, ownership of mobile phone, and below poverty line card available to the family. ${ }^{8} \mathrm{We}$ calculated regression based standardised risk ratios and corresponding confidence intervals by using the delta method for non-linear combinations of estimated parameters from the adjusted coefficients computed in logistic regression models. ${ }^{23}$

\section{Results}

When recruitment ended in March 2010, 60480 infants had been enrolled into the study. Of the 13200 caregivers due for interview on day 29, 12367 (93.7\%) were available for interview. Similarly, 6121/6600 (92.7\%) interviews due at 6 months and 4062/4388 (92.6\%) interviews due at 12 months were done (fig $1 \Downarrow$ ).

A few important differences existed between intervention and control clusters at baseline (table $1 \Downarrow$ ). The top half of the table shows characteristics obtained from the baseline survey conducted in 2006. Families in the control clusters were nearer to the highway passing through the study area $(7.0 v 15.3 \mathrm{~km})$ and had a lower proportion of home births $(65.9 \% v 71.9 \%)$ than the intervention clusters. The bottom half of the table shows characteristics of the families interviewed at infant ages 29 days and 6 and 12 months. The control clusters had features of greater urbanisation and higher socioeconomic status, reflected in more houses with private toilets $(47.7 \%$ v $38.3 \%)$ and a lower proportion of families possessing a "below poverty line" card $(11.2 \% v 17.8 \%) .{ }^{8}$ The proportion of women attending antenatal clinics was higher in the control clusters $(59.1 \% v 51.7 \%)$.

The exposure to components of the intervention has been published. ${ }^{8}$ Ninety per cent of caregivers in the intervention clusters reported being visited by a community health worker at least once in the first 10 days after the infant's birth, and $43 \%$ had the recommended three visits. Forty six per cent of mothers in the intervention clusters reported having attended at least one women's group meeting in the previous three months. ${ }^{8}$

Treatment seeking practices was a pre-specified outcome. Caregivers in the intervention clusters more often sought treatment for severe illness in neonates within 24 hours of recognition of illness (adjusted risk ratio 1.14, 95\% confidence interval 1.10 to 1.18 ) and from an appropriate provider (1.76, 1.38 to 2.24 ) (table $2 \Downarrow$ ). Caregivers were also more likely to seek treatment from an appropriate provider for diarrhoea $(22.7 \% v 12.2 \%$; adjusted risk ratio $1.96,1.38$ to 2.79$)$ and pneumonia $(27 \% v 15 \% ; 2.09,1.31$ to 3.33$)$ in the sixth month of life (table $3 \Downarrow$ ). Similar behaviours were seen at 12 months: 


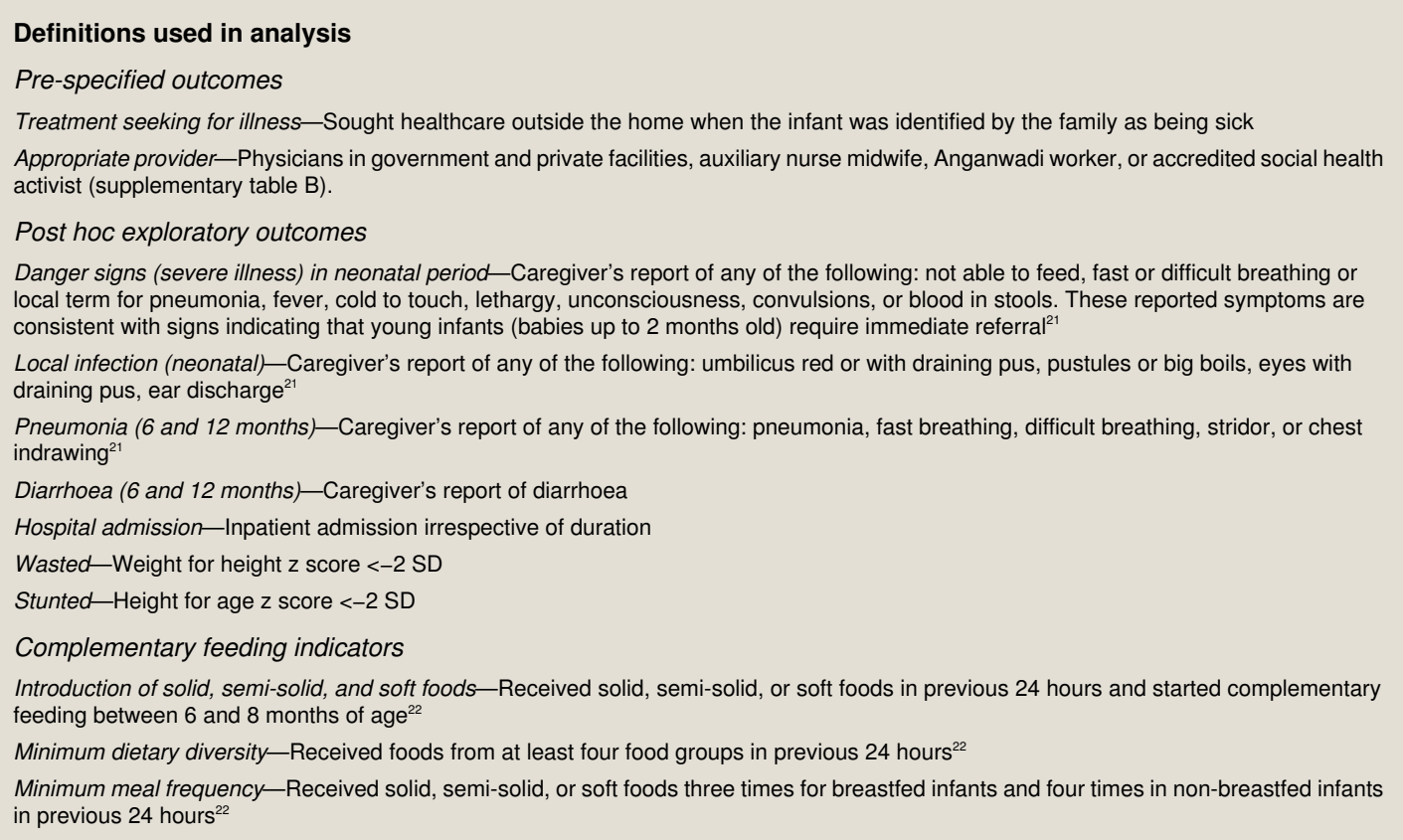

$64 \%$ versus $51 \%$ of caregivers (adjusted risk ratio $1.22,1.06$ to 1.42 ) sought treatment from appropriate providers for diarrhoea, and $18 \%$ versus $14 \%$ (adjusted risk ratio $1.44,1.00$ to 2.08 ) sought treatment from appropriate providers for pneumonia.

The proportion who did not seek care was higher in control clusters than in intervention clusters. We explored the relation between not seeking care and home treatment and found that the two were not related. The proportion of infants who had received home treatment for diarrhoea in the previous two weeks (ascertained at the interviews conducted at infant age 6 months) was similar in those who sought care and those who did not $(303 / 661(46 \%) v 92 / 205(45 \%))$. Only 9/86 (10\%) of children with pneumonia who did not seek care received home treatment compared with 20/281 (7\%) who sought care outside home.

Treatment was more often sought from the community health workers in intervention clusters than in control clusters (figures $2 \Downarrow$ and $3 \Downarrow$ ). Treatment for severe neonatal illness was more commonly sought from the Integrated Management of Neonatal and Childhood Illness trained community health workers (auxiliary nurse midwife, Anganwadi worker, or accredited social health activist) in the intervention clusters than in the control clusters $(112 / 1010(11 \%)$ v 9/1269 $(<1 \%)$; $\mathrm{P}<0.001)$ (fig $2 \Downarrow)$. In the intervention clusters, treatment seeking for local infections was also more commonly sought from community health workers $(474 / 996$ (47.6\%) v 12/1100 (1.1\%); $\mathrm{P}<0.001)$ than it was in the control clusters (fig $2 \Downarrow$ ). More caregivers sought treatment from Integrated Management of Neonatal and Childhood Illness trained community health workers for diarrhoea at 6 months in the intervention clusters $(78 / 642$ $(12.2 \%) v 6 / 866(0.7 \%)$; $\mathrm{P}<0.001)$ (fig $3 \Downarrow$ ). We saw similar trends in infants aged 12 months.

A post hoc exploratory analysis carried out for morbidity outcomes showed that fewer mothers in the intervention than in the control clusters reported signs of severe illness (adjusted risk ratio $0.82,0.67$ to 0.99$)$ and local infections $(0.91,0.71$ to 1.17) during the neonatal period (table $4 \Downarrow$ ). At 6 and 12 months, the reported symptoms suggestive of diarrhoea in the two weeks preceding the interview were lower in the intervention clusters than in the control clusters (adjusted risk ratios 0.71 ( 0.60 to 0.83 ) and 0.63 (0.49 to 0.80 ), respectively). The reported symptoms suggestive of pneumonia in the two weeks preceding the interviews were also lower at 6 and 12 months (adjusted risk ratios 0.73 (0.52 to 1.04 ) and 0.60 (0.46 to 0.78$)$, respectively) (table $4 \Downarrow$ ). Caregivers in the intervention clusters reported fewer hospital admissions in the three months preceding the interview at infant ages 6 and 12 months. Hospital admission rates may reflect a higher severity of illness, improved treatment seeking, or both.

We have reported earlier that practices for newborn care were improved in the intervention clusters. ${ }^{8}$ Caregivers in the intervention clusters continued better care practices during infancy, with a higher proportion of infants still being exclusively breast fed in the sixth month of life $(25.0 \% \mathrm{v} 11.6 \%$; adjusted risk ratio $3.19,2.67$ to 3.81 ). The proportion of infants who were stunted or wasted at 12 months of age was similar in the intervention and control clusters. Complementary feeding indicators $\mathrm{s}^{22}$ and immunisation coverage by 1 year of age were also similar. The overall immunisation coverage was low in the study areas, as we have presented numbers only when immunisation details were available on the infant immunisation card. In this setting, only a small proportion of families have immunisation cards; as the intent was to compare both groups reliably, the actual proportions may not be relevant (table $5 \Downarrow$ ).

\section{Discussion}

Following implementation of the Integrated Management of Neonatal and Childhood Illness programme, a substantial improvement was seen in treatment seeking and exclusive breastfeeding practices, as well as a reduction in hospital admissions and reporting of morbidities such as neonatal illness associated with danger signs and diarrhoea and pneumonia during infancy. These findings provide a plausible explanation for the reduction in neonatal and infant mortality previously reported in this trial. ${ }^{8}$

That lower morbidity in the intervention clusters is seen even in late infancy is noteworthy, as home visits were restricted to the neonatal period. This is likely to be the result of retention of disease prevention messages communicated during home visits and community awareness activities, particularly women's group meetings in which $45 \%$ of the target mothers' participated. $^{8}$ 
The promotion of appropriate treatment seeking practices resulted in fewer families not seeking treatment for neonatal and infant illness; of those who sought care, a greater proportion did so from the formal sector and the Integrated Management of Neonatal and Childhood Illness trained community health workers. The use of government facilities remained low, suggesting that further efforts are needed to make government facilities more acceptable to the community. Although scaling up of Integrated Management of Neonatal and Childhood Illness will increase community based treatment, children who need assessment and treatment at a higher level in the health system will always remain. Therefore, promotion of Integrated Management of Neonatal and Childhood Illness needs to be complemented by improved referral and effective, accessible, and affordable inpatient care. This is particularly important because current policy requires that young infants and neonates with serious acute bacterial infections and older children with danger signs be treated with injectable antibiotics twice daily for five days. ${ }^{17}$ The auxiliary nurse midwives and the private providers who are not medically qualified, and who are available in the community, are not currently permitted to give injections. A orientation session of about six hours was provided to the private providers. The existing government policy does not permit them to be fully trained in Integrated Management of Neonatal and Childhood Illness, as this may legitimise them. The only option, therefore, is inpatient care for the subgroup with a higher risk of death.

The recent efforts to improve healthcare infrastructure, skills and motivation of personnel, and processes and incentives to promote access to healthcare in the National Rural Health Mission are, therefore, moving in the right direction. ${ }^{24} 25$

\section{Strengths and weaknesses of study}

This was a large trial evaluating the effect of the Integrated Management of Neonatal and Childhood Illness strategy conducted at scale under programme conditions through the existing district health system, unlike in an efficacy model in a resource intensive setting. The intervention was comprehensive, focusing on newborns as well as on children aged under 5 years.

To minimise bias, we had two distinct intervention and outcome measurement teams. As this was not a blinded trial, we cannot exclude the possibility that knowledge of the intervention may have influenced the outcomes reported here; the rate of reporting of illness may be different in the two groups, resulting in reporting bias. Given that the intervention promoted early recognition and reporting of illness, over-reporting would be more likely to occur in the intervention group. We believe, therefore, that the effects of the intervention that are reported in this paper are conservative estimates of the real effects.

We chose to obtain prevalence values rather than incidence for morbidity and treatment seeking, as the intensity of data collection required for accurately measuring incidence would have increased the interaction of workers and families to an unrealistic level that may have influenced treatment seeking behaviour.

Only 18 primary health centres (the unit of randomisation) were available in Faridabad when the study was started. Choosing a smaller unit of randomisation, such as a sub-centre that covers a fifth of the population of a primary health centre, would have given us a larger number of clusters and improved randomisation and statistical efficiency. However, this would have resulted in a higher risk of contamination because health workers within a primary health centre share mechanisms for supervision, monitoring, and supply of drugs. Secondly, some important baseline differences between the intervention and control clusters remained despite the randomisation; the intervention clusters were less accessible (being further away from the highway), had a lower proportion of births in health facilities, and had families with lower economic status but higher literacy. We have adjusted for these differences in the analysis. Lastly, not all the newborns and their families received the intervention. As we wanted to do a study relevant to the programme, in which the intervention was delivered by the district health system, and not an efficacy study in which the delivery of intervention was fully controlled by the research team, a less than optimal coverage by the intervention could not be prevented. ${ }^{8}$

Differences in access to community health workers and facilities between intervention and control clusters may have influenced treatment seeking practices. However, no striking differences were apparent in the availability of different levels of care providers or access to government hospitals.

Inclusion of information on care at birth and morbidities such as perinatal asphyxia would have been useful, but the Integrated Management of Neonatal and Childhood Illness programme does not include this component. In practice, the first home visit most often takes place after the day of birth.

\section{Findings in context of similar trials}

Studies have repeatedly shown that timely and appropriate treatment seeking behaviour influences children's survival. ${ }^{11}{ }^{1426-28}$ Some of the important predictors of treatment seeking behaviour include mothers' education, knowledge, and perceived severity of illness in addition to socioeconomic factors, availability, and access. ${ }^{9}{ }^{29}$ Mothers being the primary caregivers, equipping them with the ability to identify early signs of illness prompting treatment seeking is essential. Our study shows that strengthening skills of community workers through the Integrated Management of Neonatal and Childhood Illness programme improved treatment seeking practices. The Integrated Management of Neonatal and Childhood Illness algorithm in young children has good sensitivity for detecting children with severe illness. ${ }^{30}$ As the programme is scaled up, quality of training may deteriorate and discordance with physicians' assessment may increase.$^{31}$ Careful standardisation in training is therefore critical, along with periodic retraining and effective implementation and infrastructural strengthening for long term skill retention. ${ }^{10}{ }^{32-34}$

Our intervention promoted strengthening of the health system through availability of essential medicines close to home and effective supervision. Although the improved treatment seeking from community health workers in the intervention clusters is important, a high proportion of caregivers in both clusters continued to seek treatment from the non-medically qualified private providers. On the basis of our long experience of working in this setting, we know that care is less often sought from the formal government sector, mainly because these facilities are not easily accessible owing to distance. The government facilities that are within easy reach usually function for limited hours during the day and are overcrowded, essential medicines are not available, and the doctors posted in these facilities are rude or indifferent. In contrast, the informal providers are available round the clock, are affordable, and have the unique feature of treating families on credit. Care seeking from qualified providers in the private sector is low because of their high costs and the need to travel to the town to access them. Arifeen et al have reported similar observations, in which village practitioners remained the leading source of healthcare despite increased use of government providers. ${ }^{35}$ Continued efforts are 
needed to make the government care providers and facilities more accessible to caregivers and improve access to qualified and adequately trained physicians for those who need it.

In spite of improvement in treatment seeking practices, very high rates could not be achieved overall and the plausibility of the effect on reducing mortality may be questioned. Other factors such as improved newborn care practices and exclusive breast feeding until 6 months may have also contributed to lower morbidity during infancy. Ample research evidence shows that early initiation as well as exclusive breast feeding for the first six months reduces the incidence of and mortality due to neonatal infections, diarrhoea, and pneumonia. ${ }^{15}{ }^{36-38}$ The improvement in early initiation of breast feeding in the intervention clusters may be the result of promotion at women's group meetings attended by pregnant women and their family members; this may have primed the women in pregnancy about early initiation of breast feeding and its advantages. ${ }^{8}$ The benefits of early initiation were also covered in the traditional birth attendant (dais) orientation and in the Integrated Management of Neonatal and Childhood Illness training and by

communication aids such as wall paintings in the intervention communities.

The findings of this trial need to be viewed together with those from other similar trials to draw generalisable lessons on the design and implementation features that may have influenced the level of effect. ${ }^{11}{ }^{39-43}$ A common feature of earlier trials is that they promoted recognition of illness and treatment seeking along with newborn care practices through a mix of home and community based activities. With the exception of our trial, in which the effect on neonatal and infant mortality was assessed with the intervention being targeted at newborns and children aged under 5, in all other trials the focus of the intervention and outcome assessment was on the neonatal period. Given the differences in design, implementation size, and emphasis, the effect varied across trials. ${ }^{11}$ Traditional practices and cultural beliefs have been reported to affect newborn care practices and care seeking behaviour in Indian communities. ${ }^{44}$ Greater efforts at community education and engagement to counter these may be helpful.

We hired a pool of trainers who underwent "training of trainers" by national level trainers according to the Integrated Management of Neonatal and Childhood Illness guidelines. Supervisors provided supportive supervision; vacant positions were filled by hiring contractual staff. On scaling up, however, the quality of training may vary and not meet adequate standards. ${ }^{46}$

\section{Policy implications}

The Integrated Management of Neonatal and Childhood Illness strategy promotes a simple algorithm for community health workers to identify danger signs of severe illness on the basis of easily detectable symptoms and to provide basic treatment and referral when indicated. Provision of quality training for community health workers, performance based incentives, and adequate and regular supplies of essential medicines, plus linking community level care with affordable and appropriate referral facilities, will enhance early treatment seeking and reduce the prevalence and severity of morbidities.

The lessons learnt from this and similar trials must be carefully examined in the design of national and state level programmes to reduce neonatal and infant mortality. Programme design and delivery strategies are central to the coverage and effect of interventions.

\section{Unanswered questions and future research}

Considerable scope for improvement in care practices remains, including in treatment seeking practices. The very low use of government health services indicates that identifying specific ways to improve their contribution to newborn and child health is a priority, while continuing the investments in the already clearly beneficial community health workers. Future research will be helpful in exploring possible mechanisms of improving coverage of home visits on the day of birth.

We are grateful to M K Bhan (chair, Study Advisory Group) for his insights and technical inputs throughout the study. We thank Harish Kumar and V K Anand for facilitation of the Integrated Management of Neonatal and Childhood IIIness training and providing feedback at different stages. We acknowledge the members of the Data Safety Monitoring Board: Simon Cousens (chair), Bert Pelto, and Siddarth Ramji. We thank the Government of Haryana, the civil surgeons of districts Faridabad and Palwal in position during the study for their cooperation, the participating health and Integrated Child Development Services Scheme officers, and workers of the Faridabad district. We acknowledge the cooperation extended by the population of the district who participated in the study. We are grateful for the core support provided to our organisation by the Department of Child and Adolescent Health and Development, World Health Organization (Geneva), and the Centre for Intervention Science in Maternal and Child Health (RCN project No 223269), Centre for International Health, University of Bergen (Norway).

Integrated Management of Neonatal and Childhood Illness Evaluation Study Group: Brinda Dube, Jasmine Kaur, R C Aggarwal, Divya Pandey, Amarnath Mehrotra.

Contributors: All authors contributed substantially to the design and conduct of the study, to its analysis, and to the writing of this manuscript. SM, ST, Brinda Dube, and NB were responsible for the daily implementation of the study. JM, RB, PM, HVDH, BRK, TAS, and HS provided technical inputs during all stages of the project and analysis. All authors approved the final manuscript. All authors had full access to all of the data in the study and take responsibility for the integrity of the data and accuracy of the data analysis, and their presentation. NB is the guarantor.

Funding: The study was funded by the World Health Organization, Geneva (through umbrella grant from United States Agency for International Development); the United Nations Children's Fund, New Delhi; and the Programme for Global Health and Vaccination Research of the Research Council of Norway through grant No 183722. Individual scientists at WHO and UNICEF contributed importantly to the planning, analysis, and reporting of this study. However, the central bodies of these agencies and the Research Council of Norway had no influence on how the data were collected, analysed, or presented.

Competing interests: All authors have completed the ICMJE uniform disclosure form at www.icmje.org/coi_disclosure.pdf (available on request from the corresponding author) and declare: no support from any organisation for the submitted work; no financial relationships with any organisations that might have an interest in the submitted work in the previous three years; no other relationships or activities that could appear to have influenced the submitted work.

Ethical approval: The ethics review committees of the Society for Applied Studies (IRB00001359) and the World Health Organization, Geneva $(05015 \mathrm{NCH})$ approved the study. Permissions were obtained from state and district authorities, community leaders, and women under surveillance. Women with a live birth gave informed consent before the first interview. A Study Advisory Group and a Data Safety Monitoring Board provided oversight to the study. 


\section{What is already known on this topic}

Home based newborn care interventions have shown improvement in newborn care practices, including treatment seeking behaviour leading to reduced neonatal morbidity and mortality

Integrated Management of Neonatal and Childhood Illness implementation in Haryana, India, reduced infant mortality by $15 \%$

\section{What this study adds}

The Integrated Management of Neonatal and Childhood Illness intervention implemented at scale is effective in improving treatment seeking practices

In a post hoc exploratory analysis, the intervention reduced key morbidities not only in the neonatal period but also during infancy, including a reduction in hospital admissions during infancy

These intermediate effects of the intervention provide a plausible explanation for reduction in neonatal and infant mortality

Data sharing: Requests for data sharing to the corresponding author (CHRD@sas.org.in) will be considered on approval by the Study Advisory Group.

Declaration of transparency: The lead author (study guarantor) affirms that this manuscript is an honest, accurate, and transparent account of the study being reported; that no important aspects of the study have been omitted; and that any discrepancies from the study as planned (and, if relevant, registered) have been explained.

1 World Health Organization. Children: reducing mortality. Fact sheet No 178. 2013. www. who.int/mediacentre/factsheets/fs178/en/index.html.

2 UNICEF, World Health Organization, World Bank, United Nations. Level and trends in child mortality: estimates developed by the UN Inter-Agency Group for Child Mortality Estimation. UNICEF, 2013. (available at www.childinfo.org/files/Child_Mortality_Report_ 2013.pdf).

3 Lawn JE, Cousens S, Zupan J, for the Lancet Neonatal Survival Steering Team. 4 million neonatal deaths: when? Where? Why? Lancet 2005;365:891-900.

4 International Institute for Population Sciences (IIPS), Macro International. National Family Health Survey (NFHS-3), 2005-06. IIPS, 2007.

5 World Health Organization. IMCl adaptation guide, version 5. WHO, 1998. (Document reference WHO/CHD/98.)

6 World Health Organization. Integrated management of neonatal and childhood illnesses. WHO, 2003. (Document reference: WHO/FCH/CAH.)

7 Prinja S, Mazumder S, Taneja S, Bahuguna P, Bhandari N, Mohan P, et al. Cost of delivering child health care through community level health workers: how much extra does IMNCI program cost? J Trop Pediatr 2013;59:489-95.

8 Bhandari N, Mazumder S, Taneja S, Sommerfelt H, Strand TA, for the IMNCI Evaluation Study Group. Effect of implementation of Integrated Management of Neonatal and Childhood IIIness (IMNCI) programme on neonatal and infant mortality: cluster randomised controlled trial. BMJ 2012;344:e1634.

9 De Zoysa I, Bhandari N, Akhtari N, Bhan MK. Careseeking for illness in young infants in an urban slum in India. Soc Sci Med 1998:47:2101-11.

10 Baqui AH, El-Arifeen S, Darmstadt GL, Ahmed S, Williams EK, Seraji HR, et al. Effect of community-based newborn-care intervention package implemented through two service-delivery strategies in Sylhet district, Bangladesh: a cluster-randomised controlled trial. Lancet 2008;371:1936-44.

11 Kirkwood BR, Manu A, ten Asbroek AH, Soremekun S, Weobong B, Gyan T, et al. Effect of the Newhints home-visits intervention on neonatal mortality rate and care practices in Ghana: a cluster randomised controlled trial. Lancet 2013;381:2184-92.

12 D'Souza RM. Role of health-seeking behaviour in child mortality in the slums of Karachi, Pakistan. J Biosoc Sci 2003;35:131-44.

13 Goldman N, Heuveline P. Health-seeking behaviour for child illness in Guatemala. Trop Med Int Health 2000;5:145-55.

14 Terra de Souza AC, Peterson KE, Andrade FM, Gardner J, Ascherio A. Circumstances of post-neonatal deaths in Ceara, Northeast Brazil: mothers' health care-seeking behaviours during their infants' fatal illness. Soc Sci Med 2000;51:1675-93.

15 Bhandari N, Bahl R, Mazumder S, Martines J, Black RE, Bhan MK, for the Infant Feeding Study Group. Effect of community-based promotion of exclusive breastfeeding on diarrhoeal illness and growth: a cluster randomised controlled trial. Lancet 2003:361:1418-23.

16 Bhandari N, Mazumder S, Taneja S, Dube B, Agarwal RC, Mahalanabis D, et al. Effectiveness of zinc supplementation plus oral rehydration salts compared with oral rehydration salts alone as a treatment for acute diarrhoea in a primary care setting: a cluster randomised trial. Pediatrics 2008;121:e1279-85.

17 Ministry of Health and Family Welfare. Integrated Management of Neonatal and Childhood Illness: introduction, module 1. Government of India, 2003 (available at (http://mohfw.nic. in/showfile.php?lid=546).

18 Ministry of Health and Family Welfare. IMNCI training module for workers. Government of India, 2003.

19 Ministry of Health and Family Welfare. IMNCI training module for physicians. Government of India, 2003 (available at http://mohfw.nic.in/index1.php?lang=1\&level=4\&sublinkid=553\& lid $=543$ ).

20 National Rural Health Mission. Meeting people's health needs in rural areas: framework for implementation, 2005-2012. http://nrhm.gov.in/images/pdf/about-nrhm/nrhm-frameworkimplementation/nrhm-framework-latest.pdf.

21 Ministry of Health and Family Welfare. IMNCI wall chart: assess and classify sick young infants. Government of India. (http://nrhm.gov.in/nrhm-components/rmnch-a/child-healthimmunization/child-health/guidelines.html).

22 World Health Organization. Indicators for assessing infant and young child feeding practices: conclusions of a consensus meeting held 6-8 November 2007 in Washington D.C., USA. WHO, 2008
23 Localio AR, Margolis DJ, Berlin JA. Relative risks and confidence intervals were easily computed indirectly from multivariable logistic regression. J Clin Epidemiol 2007;60:874-82. 24 Lahariya C. Cash incentives for institutional delivery: linking with antenatal and post nata care may ensure 'continuum of care' in India. Indian J Community Med 2009;34:15-8.

25 Ministry of Health and Family Welfare. National Rural Health Mission-meeting people's health needs in partnership with states: the journey so far, 2005-2010. http://nrhm.gov. in/images/pdf/media/publication/five-years-of-nrhm-2005-2010/5 years_nrhm final.pdf.

26 Hill Z, Kirkwood B, Edmond K. Family and community practices that promote child survival, growth and development: a review of the evidence. World Health Organization, 2004 (available at http://whqlibdoc.who.int/publications/2004/9241591501.pdf).

27 Amarasiri de Silva MW, Wijekoon A, Hornik R, Martines J. Care seeking in Sri Lanka: one possible explanation for low childhood mortality. Soc Sci Med 2001:53:1363-72.

28 Tsion A, Tefera B, Ayalew T, Amare D. Mothers' health care seeking behavior for childhood illnesses in Derra District, Northshoa Zone, Oromia. Ethiop J Health Sci 2008;18:87-94.

29 Sreeramareddy CT, Shankar RP, Sreekumaran BV, Subba SH, Joshi HS, Ramachandran $U$. Care seeking behaviour for childhood illness-a questionnaire survey in western Nepal. BMC Int Health Hum Rights 2006;23:6:7.

30 Mittal K, Gupta V, Khanna P, Kaushik JS, Sharma A. Evaluation of Integrated Management of Neonatal and Childhood IIIness (IMNCI) algorithm for diagnosis and referral in under-five children. Indian J Pediatr 2014;81:797-9.

31 Bhattacharyya A, Chatterjee C, Chatterjee S, Dasgupta S. A comparative study of the management decisions by $I \mathrm{MNCl}$ algorithm and by pediatricians of a teaching hospita for the children between 2 months to 5 years. Indian J Community Med 2012;37:174-9.

32 Lassi ZS, Haider BA, Bhutta ZA. Community-based intervention packages for reducing maternal and neonatal morbidity and mortality and improving neonatal outcomes. Cochrane Database Syst Rev 2010;11:CD007754.

33 Shewade HD, Aggarwal AK, Bharti B. Integrated Management of Neonatal and Childhood IIIness (IMNCI): skill assessment of health and Integrated Child Development Scheme (ICDS) workers to classify sick under-five children. Indian J Pediatr 2013;80:448-54.

34 Biswas AB, Mukhopadhyay DK, Mandal NK, Panja TK, Sinha N, Mitra K. Skill of frontline workers implementing integrated management of neonatal and childhood illness: experience from a district of West Bengal, India. J Trop Pediatr 2011;57:352-6.

35 Arifeen SE, Hoque DM, Akter T, Rahman M, Hoque ME, Begum K, et al. Effect of the Integrated Management of Childhood IIIness strategy on childhood mortality and nutrition in a rural area in Bangladesh: a cluster randomised trial. Lancet 2009;374:393-403.

36 Edmond KM, Zandoh C, Quigley MA, Amenga-Etego S, Owusu-Agyei S, Kirkwood BR. Delayed breastfeeding initiation increases risk of neonatal mortality. Pediatrics 2006:117:e380-6.

37 Bahl R, Frost C, Kirkwood BR, Edmond K, Martines J, Bhandari N, et al. Infant feeding patterns and risks of death and hospitalization in the first half of infancy: multicentre cohort study. Bull World Health Organ 2005;83:418-26.

38 Black RE, Victora CG, Walker SP, Bhutta ZA, Christian P, de Onis M, et al, for the Maternal and Child Nutrition Study Group. Maternal and child undernutrition and overweight in low-income and middle-income countries. Lancet 2013;382:427-51.

39 Kumar V, Mohanty S, Kumar A, Misra RP, Santosham M, Awasthi S, et al. Effect of community-based behaviour change management on neonatal mortality in Shivgarh, Utta Pradesh, India: a cluster-randomised controlled trial. Lancet 2008;372:1151-62.

40 Bang AT, Bang RA, Reddy HM. Home-based neonatal care: summary and applications of the field trial in rural Gadchiroli, India (1993 to 2003). J Perinatol 2005;25:S108-22.

41 Baqui A, Williams EK, Rosecrans AM, Agrawal PK, Ahmed S, Darmstadt GL, et al. Impact of an integrated nutrition and health programme on neonatal mortality in rural northern India. Bull World Health Organ 2008;86:796-804

42 Bhutta ZA, Soofi S, Cousens S, Mohammad S, Memon ZA, Ali I, Feroze A et al. Improvement of perinatal and newborn care in rural Pakistan through community-based strategies: a cluster-randomised effectiveness trial. Lancet 2011;377:403-12.

43 Darmstadt GL, Choi Y, Arifeen SE, Bari S, Rahman SM, Mannan I, et al. Evaluation of a cluster-randomized controlled trial of a package of community-based maternal and newborn interventions in Mirzapur, Bangladesh. PLoS One 2010;5:e9696

44 Upadhyay RP, Singh B, Rai SK, Anand K. Role of cultural beliefs in influencing selected newborn care practices in rural Haryana. J Trop Pediatr 2012;58:406-8.

45 Kesterton AJ, Cleland J. Neonatal care in rural Karnataka: healthy and harmful practices, the potential for change. BMC Pregnancy Childbirth 2009;9:20.

46 Mohan P, Kishore B, Singh S, Bahl R, Puri A, Kumar R. Assessment of implementation of integrated management of neonatal and childhood illness in India. $J$ Health Popul Nutr 2011;29:629-38.

\section{Accepted: 23 July 2014}

\section{Cite this as: BMJ 2014;349:94988}

This is an Open Access article distributed in accordance with the Creative Commons Attribution Non Commercial (CC BY-NC 3.0) license, which permits others to distribute, remix, adapt, build upon this work non-commercially, and license their derivative works on different terms, provided the original work is properly cited and the use is non-commercial. See: http://creativecommons.org/licenses/by-nc/3.0/. 


\section{Tables}

Table 1/ Cluster level and individual level characteristics of intervention and control communities at baseline. Values are numbers (percentages) unless stated otherwise

\begin{tabular}{|c|c|c|}
\hline Baseline characteristics & Intervention & Control \\
\hline Cluster level characteristics* & ( $n=9$ clusters $)$ & ( $n=9$ clusters $)$ \\
\hline Mean (SD) home births (\%) & $71.9(8.9)$ & $65.9(13.4)$ \\
\hline Mean (SD) illiterate mothers (\%) & $50.1(9.0)$ & $51.5(13.9)$ \\
\hline Median (interquartile range) population per cluster & 38295 (30 140-65 332) & 40539 (38 250-49 869) \\
\hline $\begin{array}{l}\text { Mean (SD) distance between cluster primary health centre } \\
(\mathrm{km})\end{array}$ & $15.3(11.7)$ & $7.0(5.2)$ \\
\hline Mean (SD) neonatal mortality rate & $32.6(8.1)$ & $32.4(9.1)$ \\
\hline Mean (SD) infant mortality rate & $44.9(14.7)$ & $43.9(10.7)$ \\
\hline Individual level characteristics $†$ & $(n=11322)$ & $(n=11228)$ \\
\hline Illiterate mother & $4438(39.2)$ & $4901(43.6)$ \\
\hline Schedule caste or tribe & $2845(25.1)$ & $2704(24.1)$ \\
\hline Median (interquartile range) No of family members & $7(5-10)$ & $7(5-9)$ \\
\hline Mother working outside home & $375(3.3)$ & $436(3.9)$ \\
\hline Median (interquartile range) annual income (rupees) & $60000(36000-100000)$ & $50000(36000-80000)$ \\
\hline Toilet inside house & $4333(38.3)$ & $5355(47.7)$ \\
\hline Family below poverty line card & $2011(17.8)$ & $1255(11.2)$ \\
\hline Possess mobile phone & $8255(72.9)$ & $8483(75.6)$ \\
\hline Deliveries conducted by traditional birth attendants (dais) & $6415(56.7)$ & $4953(44.1)$ \\
\hline Home births & $7327(64.7)$ & 6018 (53.6) \\
\hline Attended antenatal clinics & $3210 / 6204(51.7)$ & $3642 / 6163(59.1)$ \\
\hline
\end{tabular}

*From baseline survey (in 2006).

†Of families of caregivers interviewed at infant ages 29 days, 6 months, or 12 months (in 2008 to 2010). 
Table 2| Treatment seeking practices reported by caregivers of infants who were sick during neonatal period in intervention and control communities (pre-specified analysis). Values are numbers (percentages) unless stated otherwise

\begin{tabular}{|c|c|c|c|}
\hline Treatment seeking practices & Intervention clusters & Control clusters & Risk ratio $(95 \% \mathrm{Cl})^{*}$ \\
\hline Newborns with danger signst & $(n=1010)$ & $(n=1269)$ & \\
\hline Sought treatment from any provider & $964(95.5)$ & $1158(91.3)$ & 1.05 (1.02 to 1.07$)$ \\
\hline $\begin{array}{l}\text { Sought treatment within } 24 \text { hours of illness } \\
\text { recognition }\end{array}$ & $805(79.7)$ & $874(68.9)$ & 1.14 (1.10 to 1.18$)$ \\
\hline Sought treatment from appropriate provider & $474(46.9)$ & $374(29.5)$ & $1.76(1.38$ to 2.24$)$ \\
\hline Newborns with local infection§ & $(\mathrm{n}=996)$ & $(n=1100)$ & \\
\hline Sought treatment from any provider & $794(79.7)$ & $648(58.9)$ & $1.42(1.33$ to 1.52$)$ \\
\hline $\begin{array}{l}\text { Sought treatment within } 24 \text { hours of illness } \\
\text { recognition }\end{array}$ & $474(47.6)$ & $278(25.3)$ & 1.97 (1.71 to 2.27$)$ \\
\hline Sought treatment from appropriate providerł & $577(57.9)$ & $138(12.5)$ & 4.86 (3.80 to 6.21$)$ \\
\hline
\end{tabular}

*Using adjusted logistic regression models with delta method for non-linear combinations (to obtain risk ratio) adjusted for cluster design and potential confounders (toilet inside house, illiterate mother, schedule caste or tribe, possession of mobile phone, family with below poverty line card, distance from primary health centre to nearest point on highway, percentage of home births in cluster).

†In young infants up to 2 months - caregiver's report of any of the following: not able to feed, fast or difficult breathing or local term for pneumonia, fever, cold to touch, lethargy, unconsciousness, convulsions, or blood in stools; these reported symptoms are consistent with signs that fall in red zone of colour coded Integrated Management of Neonatal and Childhood Illness charts and require immediate referral.

†Physician in government and private facilities or community health worker (auxiliary nurse midwife, Anganwadi worker, or accredited social health activist). §In neonate-caregiver's report of any of the following: umbilicus red or draining pus, pustules or big boils, eyes with draining pus, or ear discharge. 
Table 3| Treatment seeking practices reported by caregivers at infant age 6 and 12 months in intervention and control communities (pre-specified analysis). Values are numbers (percentages) unless stated otherwise

\begin{tabular}{|c|c|c|c|}
\hline Treatment seeking practices & Intervention clusters & Control clusters & Risk ratio $(95 \% \mathrm{Cl})^{\star}$ \\
\hline $\begin{array}{l}\text { Infants aged } 6 \text { months with diarrhoeat in } 2 \text { weeks } \\
\text { preceding interview }\end{array}$ & $(n=642)$ & $(n=866)$ & \\
\hline Sought treatment from any provider & $509(79.3)$ & $661(76.3)$ & $1.04(0.99$ to 1.08$)$ \\
\hline Sought treatment within 24 hours of illness recognition & $334(52.0)$ & $420(48.5)$ & $1.10(0.94$ to 1.29$)$ \\
\hline Sought treatment from appropriate provider $\ddagger$ & $146(22.7)$ & $106(12.2)$ & 1.96 (1.38 to 2.79$)$ \\
\hline $\begin{array}{l}\text { Infants aged } 12 \text { months with diarrhoeat in } 2 \text { weeks } \\
\text { preceding interview }\end{array}$ & $(n=425)$ & $(n=661)$ & \\
\hline Sought treatment from any provider & $310(73)$ & $487(73.7)$ & 0.95 (0.87 to 1.03$)$ \\
\hline Sought treatment within 24 hours of illness recognition & $227(53)$ & $352(53.3)$ & $0.99(0.89$ to 1.10$)$ \\
\hline Sought treatment from appropriate provider $\ddagger$ & $271(64)$ & $337(51.0)$ & $1.22(1.06$ to 1.42$)$ \\
\hline $\begin{array}{l}\text { Infants aged } 6 \text { months with pneumonia§ in } 2 \text { weeks } \\
\text { preceding interview }\end{array}$ & $(n=269)$ & $(n=375)$ & \\
\hline Sought treatment from any provider & $237(88)$ & $289(77)$ & $1.19(1.11$ to 1.26$)$ \\
\hline Sought treatment within 24 hours of illness recognition & $198(74)$ & $217(58)$ & $1.31(1.16$ to 1.48$)$ \\
\hline Sought treatment from appropriate provider $\ddagger$ & $72(27)$ & $56(15)$ & 2.09 (1.31 to 3.33$)$ \\
\hline $\begin{array}{l}\text { Infants aged } 12 \text { months with pneumonia§ in } 2 \text { weeks } \\
\text { preceding interview }\end{array}$ & $(n=112)$ & $(n=199)$ & \\
\hline Sought treatment from any provider & $91(81)$ & $155(78)$ & $1.05(0.94$ to 1.19$)$ \\
\hline Sought treatment within 24 hours of illness recognition & $69(62)$ & $121(61)$ & $1.10(0.96$ to 1.25$)$ \\
\hline Sought treatment from appropriate provider $\ddagger$ & $20(18)$ & $28(14)$ & 1.44 (1.00 to 2.08$)$ \\
\hline
\end{tabular}

*Using adjusted logistic regression models with delta method for non-linear combinations (to obtain risk ratio) adjusted for cluster design and potential confounders (toilet inside house, illiterate mother, schedule caste or tribe, possession of mobile phone, family with below poverty line card, distance from primary health centre to nearest point on highway, percentage of home births in cluster).

†Caregiver's report of diarrhoea.

‡Physicians in government and private facilities or community health workers (auxiliary nurse midwife, Anganwadi worker, or accredited social health activist). §Caregiver's report of any of the following: pneumonia, fast breathing, difficult breathing, stridor, or chest indrawing. 
Table 4| Illness and hospital admissions reported during neonatal period and at infant ages 6 and 12 months in intervention and control communities (post hoc exploratory analysis). Values are numbers (percentages) unless stated otherwise

\begin{tabular}{|c|c|c|c|}
\hline Outcomes & Intervention clusters & Control clusters & Risk ratio $(95 \% \mathrm{Cl})^{*}$ \\
\hline Illness in neonatal period & $(n=6204)$ & $(n=6163)$ & \\
\hline Danger signs $†$ & $1010(16.3)$ & $1269(20.6)$ & $0.82(0.67$ to 0.99$)$ \\
\hline Local infection $\ddagger$ & $996(16.1)$ & $1100(17.8)$ & $0.91(0.71$ to 1.17$)$ \\
\hline \multicolumn{4}{|l|}{ Admitted to hospital one or more times in neonatal } \\
\hline \multicolumn{4}{|l|}{$\begin{array}{l}\text { Illness during infancy (in } 2 \text { week period before } \\
\text { interview) }\end{array}$} \\
\hline Interview at infant age 6 months: & $(n=3073)$ & $(n=3048)$ & \\
\hline Diarrhoea§ irrespective of other illnesses & $642(20.9)$ & $866(28.4)$ & $0.71(0.60$ to 0.83$)$ \\
\hline Pneumoniaף irrespective of other illnesses & $269(8.8)$ & $375(12.3)$ & $0.73(0.52$ to 1.04$)$ \\
\hline $\begin{array}{l}\text { Admitted to hospital }{ }^{* *} \text { one or more times in } \\
\text { previous } 3 \text { months }\end{array}$ & $163(5.3)$ & $214(7.0)$ & $0.87(0.58$ to 1.30$)$ \\
\hline Interview at infant age 12 months: & $\mathrm{n}=2045$ & $\mathrm{n}=2017$ & \\
\hline Diarrhoea§ irrespective of other illness & $425(20.8)$ & $661(32.8)$ & $0.63(0.49$ to 0.80$)$ \\
\hline Pneumoniaף irrespective of other illness & $112(5.5)$ & $199(9.9)$ & 0.60 (0.46 to 0.78$)$ \\
\hline $\begin{array}{l}\text { Admitted to hospital }{ }^{* *} \text { one or more times in } \\
\text { previous } 3 \text { months }\end{array}$ & $108(5.3)$ & $165(8.2)$ & 0.67 (0.51 to 0.88$)$ \\
\hline
\end{tabular}

*Using adjusted logistic regression models with delta method for non-linear combinations (to obtain risk ratio) adjusted for cluster design and potential confounders (toilet inside house, illiterate mother, schedule caste or tribe, possession of mobile phone, family with below poverty line card, distance from primary health centre to nearest point on highway, percentage of home births in cluster).

†In young infants up to 2 months-caregiver's report of any of the following: not able to feed, fast or difficult breathing or local term for pneumonia, fever, cold to touch, lethargy, unconsciousness, convulsions, or blood in stools; these reported symptoms are consistent with signs that fall in red zone of colour coded Integrated Management of Neonatal and Childhood Illness charts and require immediate referral.

łln neonate—caregiver's report of any of the following: umbilicus red or draining pus, pustules or big boils, eyes with draining pus, or ear discharge.

$\S$ Caregiver's report of diarrhoea.

ףCaregiver's report of any of the following: pneumonia, fast breathing, difficult breathing, stridor, or chest indrawing

${ }^{* *}$ Inpatient admission irrespective of duration; includes admission in oral rehydration units for administration of oral rehydration salts or clinics for nebulisation. 
Table 5| Post-neonatal infant care practices and nutritional status in intervention and control communities (post hoc exploratory analysis). Values are numbers (percentages) unless stated otherwise

\begin{tabular}{|c|c|c|c|}
\hline Outcomes & Intervention clusters & Control clusters & Risk ratio $(95 \% \mathrm{Cl})^{\star}$ \\
\hline \multicolumn{4}{|l|}{ Feeding practices } \\
\hline Exclusively breast fed at 6 months & $768 / 3073(25.0)$ & $353 / 3048(11.6)$ & 3.19 (2.67 to 3.81$)$ \\
\hline Continued breast feeding at 12 months & $1748 / 2045(85.5)$ & $1679 / 2017(83.2)$ & $1.02(1.00$ to 1.04$)$ \\
\hline Nutritional status at 12 months & $(n=1461)$ & $(n=1412)$ & \\
\hline Proportion wasted (<-2 SD WFH Z score) & $243(16.6)$ & $202(14.3)$ & $1.10(0.90$ to 1.36$)$ \\
\hline Proportion stunted (<-2 SD HFA Z score ) & $725(49.6)$ & $680(48.2)$ & $0.99(0.94$ to 1.04$)$ \\
\hline Complementary feeding indicators & $(n=2045)$ & $(n=2017)$ & \\
\hline $\begin{array}{l}\text { Received solid, semi-solid, or soft foods in previous } 24 \\
\text { hours and started complementary feeding between } 6 \\
\text { and } 8 \text { months of age }\end{array}$ & $687(33.6)$ & $759(37.6)$ & 0.92 (0.82 to 1.02$)$ \\
\hline Received foods from $\geq 4$ food groups in previous 24 hours & $109(5.3)$ & $175(8.7)$ & $0.68(0.42$ to 1.09$)$ \\
\hline $\begin{array}{l}\text { Received solid, semi-solid, or soft foods } 3 \text { times for } \\
\text { breastfed infants and } 4 \text { times in non-breastfed infants in } \\
\text { previous } 24 \text { hours }\end{array}$ & $534(26.1)$ & $787(39.0)$ & $0.72(0.58$ to 0.89$)$ \\
\hline Immunisation coverage by 12 months of age & $(n=2045)$ & $(n=2017)$ & \\
\hline Received BCG vaccine & $489(23.9)$ & $552(27.4)$ & $1.08(0.76$ to 1.54$)$ \\
\hline Received third dose of DPT vaccine & $318(15.6)$ & $427(21.2)$ & 0.95 (0.68 to 1.33$)$ \\
\hline Received measles vaccine & $226(11.1)$ & $339(16.8)$ & $0.92(0.65$ to 1.30$)$ \\
\hline
\end{tabular}

DPT=diphtheria, tetanus, and pertussis; HFA=height for age; WFH=weight for height.

*Using adjusted logistic regression models with delta method for non-linear combinations (to obtain risk ratio) adjusted for cluster design and potential confounders (toilet inside house, illiterate mother, schedule caste or tribe, possession of mobile phone, family with below poverty line card, distance from primary health centre to nearest point on highway, percentage of home births in cluster). 


\section{Figures}

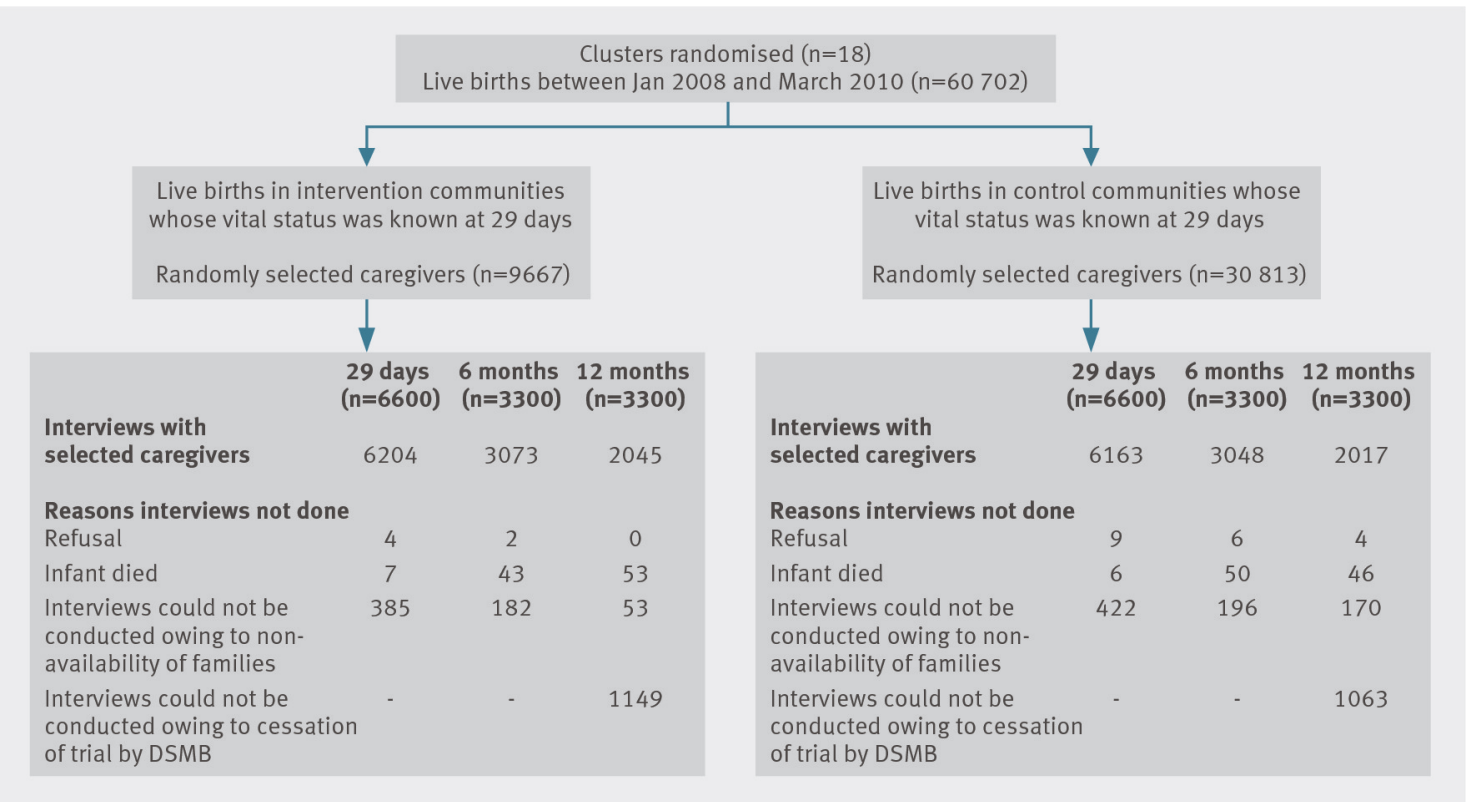

Fig 1 Trial profile. DSMB=Data Safety Monitoring Board
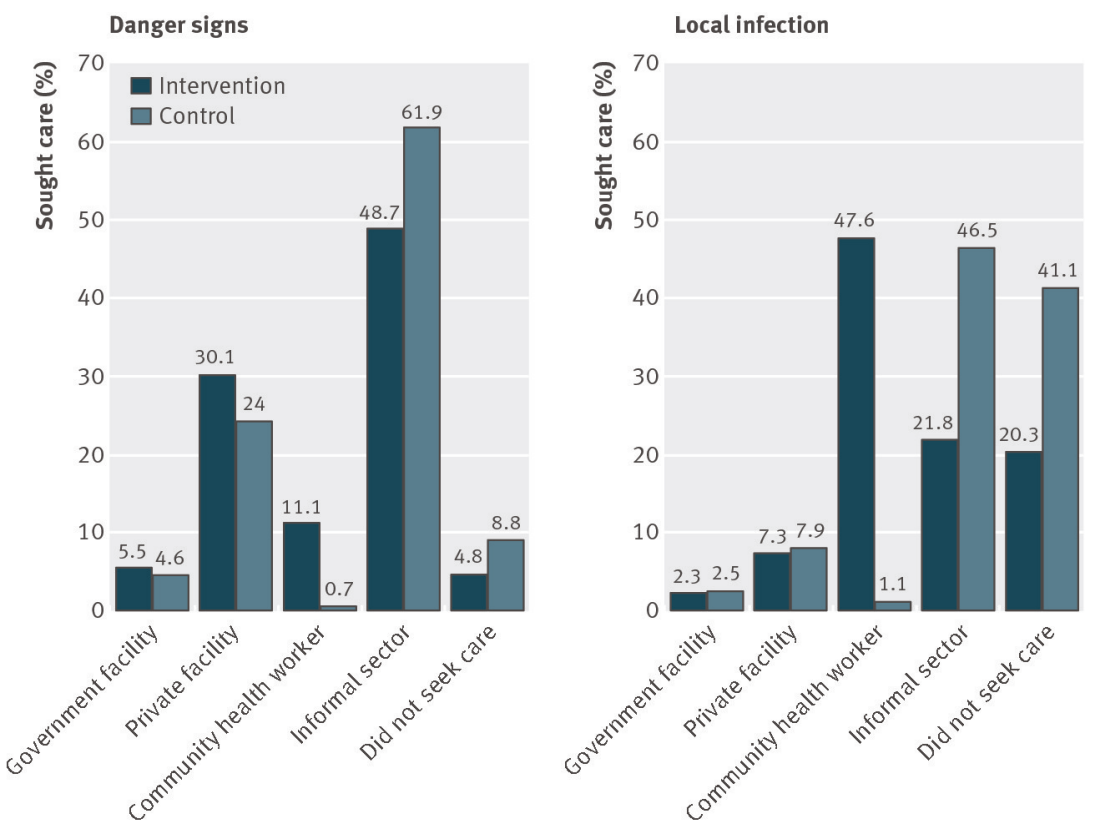

Fig 2 Treatment seeking practices during neonatal period ascertained through caregivers' interviews on day 29 in intervention and control communities (pre-specified analysis). Government facility=physicians in government hospital and primary health centres; private facility=physicians in private hospital or nursing home; community health workers=auxiliary nurse midwives, Anganwadi workers, or accredited social health activists; informal sector=private providers not medically qualified, chemists, or traditional healers such as baba, vaid, or bhagat 


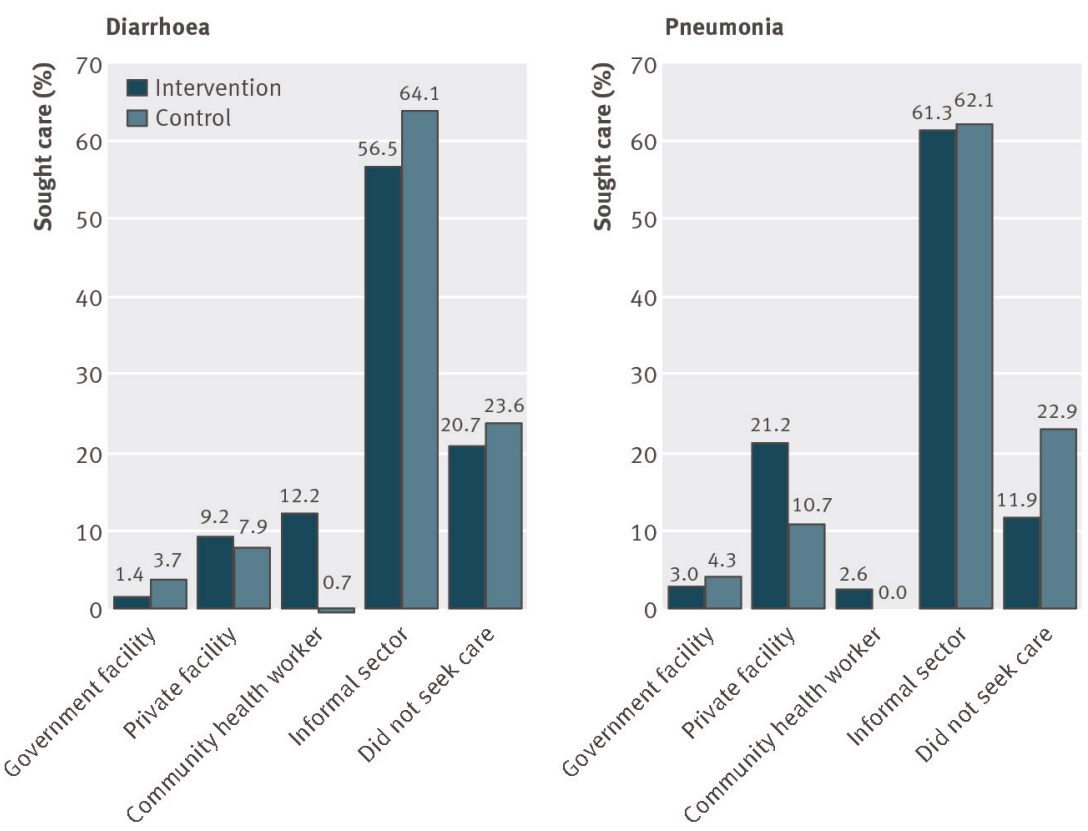

Fig 3 Treatment seeking practices for infants at age 6 months ascertained through caregivers' interviews in intervention and control communities (pre-specified analysis). Definitions as for figure 2 